fitting is the grim epilogue on the effects of atomic warfare, a reminder to be prepared not only in the light of experiences gained in the last war but with the aid of the present peace-time advances.

This book is more than a military surgical history. Thanks to carefully documented experience, it contains a great deal of the utmost value in civilian practice. It should be read by every surgeon.

G.F.H.

\section{THE MEDICAL ANNUAL, 1954}

Edited by Sir Henry Tidy, K.B.E., M.A., M.D., F.R.C.P., and R. MILNES WALKER, M.S., F.R.C.SPp. xiv +524 , with 67 plates and 32 illustrations. Bristol: John Wright \& Sons, Ltd. 1954. 32s. $6 \mathrm{~d}$.

No more recommendation is needed for the 72nd volume of the Medical Annual than to say that it maintains the high standard of its predecessors. In a comprehensive review of the recent literature in all branches of medical science it includes subjects of such general and topical interest as lung cancer and tobacco smoking, the therapeutic applications of cortisone, detergents and the skin, and claims for negligence. The specialist sections are again filled with critically selected material of much practical and academic interest.

\section{THE ANATOMY OF THE BRONCHIAL TREE}

By R. C. Brock, M.S., F.R.C.S., F.A.C.S. 2nd Edition. Pp. viii +243 , with 158 illustrations, some in colour. London: Geoffrey Cumberlege. r 954 . 45s.

The second edition of this monograph presents a full revision of the author's work in this sphere. Drawing upon his later experience, he has expanded some parts of the text and the recent work of other authorities is correlated, so that an up-to-date survey of present knowledge is set out. An important step is taken towards standardization of bronchial nomenclature, by the adoption throughout of the recommendations of the Committee of the 1949 International Congress of Otolaryngology. A few new illustrations are added to the very fine collection printed in the first edition, and the layout has been rearranged in an effort to facilitate reference to them during study of the text.

It is superfluous to comment on the importance of this treatise, which has long been acknowledged. It is, however, pertinent to commend the author's simple and readable presentation, which makes his book a pleasure to study.

$$
\text { H.J.G. }
$$

\section{FRENCH'S INDEX OF DIFFERENTIAL DIAGNOSIS}

Edited by A. H. Douthwaite, M.D., F.R.C.P. Seventh Edition. Pp. xii $+1,046$, with 731 illustrations, 200 in colour. Bristol: John Wright \& Sons Ltd. 1954. £5 5s.

This is the seventh edition and the eighteenth printing of a book which first appeared in 1912. These facts attest to its perennial popularity. This edition is edited by A. H. Douthwaite and continues the Guy's tradition, and the contributors are all men who have made original contributions in their own fields. This is not a book to read right through (even if it were to be so used it would be useful reading) but rather to keep beside while reading a medical textbook. It is as a supplement to any formal textbook of medicine that it is recommended both for examination reading and long afterwards by the postgraduate student.

The publishers are to be congratulated on the excellence of their production; the illustrations and above all the index are models and the whole format is attractive, and the limp covers make it just possible to hold this book on the knee while reading, in spite of its generous size.

H.J.A.

\section{RECENT DEVELOPMENTS IN PSYCHO- SOMATIC MEDICINE}

Edited by ERIC D. WitTKower, M.D., and R. A. Cleghorn, M.D., D.Sc. Pp. xvi +495, illustrated. London: Sir Isaac Pitman \& Sons Ltd. 1954. 5 os.

This book is concerned with the relation of the mind to the onset and course of disease. There are 29 contributors, the majority of whom write from Canada or the U.S.A. There are eight chapters on general topics and 17 on psychological aspects of specified diseases or groups of diseases. Each chapter contains an up-to-date bibliography.

The standard of the contributions varies considerably, but together they reveal some of the main difficulties inherent in studies in this field. Perhaps the greatest difficulty is the intangibility of the indices measured so that objective recording is hard to attain. Many studies, too, by their very nature, concern only few subjects who, one suspects, may have been selected largely for their psychological interest. The most impressive contributions are those dealing with the elements of the subject. These include anatomical and physiological studies of different parts of the brain, and expositions of methods at present available for research in man - and their limitations. The postgraduate reader will find these and many other chapters stimulating and of great interest.

R.R.H.L. 